a description of the main illness in such infants-respiratory distress syndrome, and the last 5 chapters in the book cover other respiratory illnesses, neurological problems, infections, jaundice and malformations.

There are particularly good descriptions of general aspects of neonatology such as the interpretation of perinatal statistics, the management of mother-child attachment, talking to parents, minimal handling of sick infants, resuscitation, and the care and examination of the normal fullterm newborn, though the section on infant feeding would benefit from showing some more conviction about the benefits of the new whey-based infant formulas, and a table showing the composition of different milks would also be helpful.

Dr Vulliamy's apparent unwillingness to commit himself about which type of milk to give, is typical of the book as a whole. The approach is, in general, discursive rather than didactic, and specific illness orientated rather than clinical problem orientated. While it might be said that this gives a fairer view of the subject, in this type of short book there is a risk of confusing the reader, and it also seriously reduces the book's value as a practical guide even for the management of healthy fullterm infants. The lack of problem orientation means that it is not possible to look up what to do with a grunting neonate, or a possibly infected baby-perhaps the two commonest clinical situations which confront a nurse or a resident in a maternity hospital.

Although the topics covered in the second half of the book have been 'modernised' for this 5th edition, there is still some imbalance, and an old fashioned feel about it. Neonatal hypocalcaemic fits and intracerebral birth trauma are now virtually extinct; choanal atresia, galactosaemia and epispadias are extremely rare, yet all these conditions receive much more attention than common problems such as meconium aspiration or transient tachypnoea; intraventricular haemorrhage, now the commonest cause of death in the neonatal period, is scarcely mentioned. Many of the rarer conditions mentioned would be better dealt with by much freer use of diagrams and/or tables. The author-or the editors-have some difficulty in converting from old to new units; a $\mathrm{PO}_{2}$ of $100 \mathrm{mmHg}$ is $13 \mathrm{kPa}$ in some places and $14 \mathrm{kPa}$ in others, and it is particularly sad to see the seriously incorrect conversion of $2 \frac{1}{2} \mathrm{oz} / \mathrm{lb}$ to $150 \mathrm{ml} / \mathrm{kg}$ being perpetuated yet again.

These are, however, minor criticisms of what is, and, despite the presence of a plethora of new books on the care of very sick infants, will justifiably remain a popular primer for those working with newborn babies. Furthermore, at $£ 5.95$, it is a bargain.

N. R. C. ROBERTON.

Addenbrooke's Hospital,

Cambridge CB2 2QQ

Phenoxybenzamine in Disorders of Micturition. Proceedings of a symposium held at the Cavendish Conference Centre, London November 1981

Edited by W. Keith Yeates. Pp. 103, illustrated. Smith Kline and French, Welwyn Garden City, 1982. Free of charge.

Although this is a give-away from a drug company, and has all the makings of a dreary write-up of a symposium designed to puff a pharmaceutical preparation, it is, in fact, a very valuable collection of important essays on one of the most interesting aspects of modern urology. It is an oversimplification to say that because there are alpha-adrenergic receptors in the smooth muscle around the bladder neck, when the bladder neck fails to relax, it will do good to block these fibres by giving phenoxybenzamine; nevertheless, giving the drug does do good, and may put off or even avoid, an operation to cut or remove obstructing tissue at the neck of the bladder. However, alpha-receptors are not confined to the neck of the bladder, and when they are blocked, results are by no means so clear cut. In this excellent little book, the clinical uses of phenoxybenzamine are clearly set out by Marco Caine, who first used it extensively, and its physiology clearly described by McGuire and Gibbon. The message is clear, this drug has an important place in the management of a wide range of patients with different disorders of urination, but it must be used intelligently and with proper circumspection. It is not, and never was pretended to be-'a pill for the prostate'. It is, however, a very useful drug and this is an excellent guide to those who wish to use it.

J. P. BLANDY,

London Hospital Medical College, London E1 2AD.

\section{Recent Advances in Geriatric Medicine No. 2}

Edited by Bernard IsAacs. Pp. viii +283 , illustrated. Churchill

Livingstone, Edinburgh and London, 1982. £12.00.

The quality of Professor Isaacs' second 'Recent advances in Geriatric Medicine' makes one regret the 4 year interval since the first. The book is divided under two headings. The first is 'Content' which comprises assessment, treatment, gerontology, and epidemiology. The article by Professor Sleight on cardiac pacing is particularly impressive. Others cover various subjects and their pharmacology, one being hypnotics, which are surely the most paradoxical of drugs, being purely subtractive, saving no lives, yet they are among the most widely used and the most dangerous. Gerontology is well served, particularly by Professor Burnet on ageing. Psychiatry concerns us all, especially since the R.C.P. report on dementia and the materialisation of the psychogeriatrician. Dr Bergmann's description of the "cloak of invisibility that covers the elderly depressive' rings particularly true.

The book's second heading is 'Organisation'. Professor Prinsley reports the solutions that are developing in Australia. The Multitier Geriatric Complex provides complete care on one campus-an attractive concept, but the old lunatic asylum did just that, at an unacceptable cost in isolation and human dignity. Such a unit must at all costs, relate, to the community it serves.

Professor Isaacs and Dr Horrocks present 2 almost incompatible views of the future. The 'Physician with an Interest' does geriatrics part-time - can his commitment to the elderly be any more than part-time? Dr Horrocks' geriatrician certainly is totally committed Perhaps in the future he could develop his own 'interest'? Dr Horrocks' concept has been outstandingly successful for 12 years. The crucial point, however, is that only District General Hospital beds are capable of being used to the necessary efficiency by either type of physician. Peripheral beds cannot but be static and inefficient.

There is much to praise, and little to criticise in this controversial and stimulating book.

\section{J. HIRSH, Barnet General Hospital, \\ Barnet, \\ Herts EN5 3DJ.}

\section{Tutorials in Differential Diagnosis}

By E. R. Beck, J. L. Francis and R L. Souhami. 2nd edn. Pp. 299, illustrated. Pitman Books, London, 1982. £7.50.

'What is the use of a book' thought Alice 'without pictures or conversations'. Thus thought Alice in Wonderland, and the present plethora of new books has caused similar thoughts to pass through my mind on numerous occasions. Most books will, undoubtedly, end up on library shelves gathering dust, but here is an outstanding exception. It has a purpose, it is undoubtedly useful, and it will be bought. It would be of some value to undergraduate students, but its main audience must be the M.R.C.P. aspirant, for whom it is a must. It is also appealing to those who have made it, but who wish to keep up-to-date, and it is also helpful as an aide to thinking about a difficult diagnostic problem.

Its format is unusual but works well. The authors have selected signs and symptoms commonly encountered in clinical practice and discussed them with the emphasis on those features of the history and examination which are important in differential diagnosis. This 